\title{
THỰC TRẠNG GIŨ GÌN VÀ PHÁT HUY PHONG CÁCH NGƯờI ĐÀ LẠT HIỀN HÒA, THANH LỊCH, MẾN KHÁCH
}

\author{
Võ Thuấn ${ }^{\mathrm{a}^{*}, \text { Trần Thị Minh Phươnga }}$
}

${ }^{a}$ Khoa Xã hội học và Công tác xã hội, Truoòng Đại học Đà Lạt, Lâm Đồng, Việt Nam

"Tác giả liên hệ: Email: thuanv@dlu.edu.vn

Lịch sử bài báo

Nhận ngày 14 tháng 01 năm 2020

Chỉnh sửa ngày 16 tháng 02 năm 2020 | Chấp nhận đăng ngày 17 tháng 02 năm 2020

\section{Tóm tắt}

Trong quá trình xây dưng và phát triển thành phố, ngườ Đà Lạt luôn thể hiện sự hiền hòa, thanh lịch, mến khách. Mục đỉch của bài báo này tập trung phân tích hệ thống nhũng uu điểm, thành tưu, cũng nhu nhũng nhược điểm, hạn chế trong giũu gìn và phát huy phong cách người Đà Lạt hiền hòa, thanh lịch, mến khách bằng việc phân tích các tài liệu thứ cấp, các dũ liệu định tính và định luợng qua quá trình khảo sát thực tế. Bên cạnh sự mô tả phong cách người Đà Lạt, việc phân tích các yếu tố tác động tích cực và tiêu cực đến giũ gìn và phát huy phong cách nguời Đà Lạt cũng được nhấn mạnh. Đồng thời chỉ rõ các chủ thể đã thực hiện trách nhiệm của minh nhu thế nào đối với việc giữ gìn và phát huy phong cách người Đà Lạt trong quá trình hội nhập và phát triển.

Từ khóa: Đà Lạt; Hiền hòa; Mến khách; Phong cách; Thanh lịch.

DOI: http://dx.doi.org/10.37569/DalatUniversity.10.1.714(2020)

Loại bài báo: Bài báo nghiên cứu gốc có bình duyệt

Bản quyền (C) 2020 (Các) Tác giả.

Cấp phép: Bài báo này được cấp phép theo CC BY-NC 4.0 


\title{
THE REALITY OF PRESERVING AND PROMOTING THE GENTLE, ELEGANT, AND HOSPITABLE STYLE OF DALAT PEOPLE
}

\author{
Vo Thuan ${ }^{a *}$, Tran Thi Minh Phuonga \\ ${ }^{a}$ The Faculty of Sociology and Social Work, Dalat University, Lamdong, Vietnam \\ *Corresponding author: Email: thuanv@dlu.edu.vn \\ Article history \\ Received: January $14^{\text {th }}, 2020$ \\ Received in revised form: February $16^{\text {th }}, 2020 \mid$ Accepted: February $17^{\text {th }}, 2020$
}

\begin{abstract}
In the process of building and developing the city Dalat, its citizens have always been gentle, elegant, and hospitable. The purpose of this article is to analyze and systemize the advantages, achievements as well as drawbacks and limitations in preserving and promoting the gentle, elegant, and hospitable style of living of Dalat people, using secondary documents, qualitative, and quantitative data through surveys. Besides the detailed description of these characteristics, an analysis of factors that positively and negatively affect the preservation and promotion of Dalat people's style is also emphasized. At the same time, the paper shows how the subjects have fulfilled their responsibilities to preserve and promote the style of Dalat people in the process of integration and development.
\end{abstract}

Keywords: Dalat; Elegant; Gentle; Hospitality; Style.

DOI: http://dx.doi.org/10.37569/DalatUniversity.10.1.714(2020)

Article type: (peer-reviewed) Full-length research article

Copyright (c) 2020 The author(s).

Licensing: This article is licensed under a CC BY-NC 4.0 


\section{1. ĐặT VẤN ĐỀ}

Theo số liệu của ngành thống kê của tỉnh Lâm Đồng năm 2019, dân số Đà Lạt có 227,002 người. "Trong năm 2019, khách du lịch đến Lâm Đồng đạt 7,160,000 lượt. Trong đó khách quốc tế đạt 533,000 lượt và khách nội địa đạt 6,627,000. Khách qua lưu trú đạt $4,860,000$ lượt. Ngày lưu trú bình quân là 2.1 ngày. Tổng thu từ khách du lịch trên địa bàn tỉnh đạt 12,888 tỷ đồng (tăng $10.1 \%$ so với năm 2018). Nhìn chung, lượng khách du lịch đến Lâm Đồng trong năm 2019 tăng so với cùng kỳ năm 2018; Một số thị trường khách quốc tế tăng mạnh so với năm 2018 (như: Hàn Quốc tăng hơn $80 \%$, Malaysia tăng 21\%)" (Sở Văn hóa Thể thao và Du lịch tỉnh Lâm Đồng, 2020). Dựa trên phương pháp phỏng vấn bằng bảng hỏi, nhóm nghiên cứu ${ }^{1}$ chúng tôi đã gặp gỡ và xin ý kiến của 1,246 người, bao gồm cả khách du lịch và người dân ở Đà Lạt (599 du khách (tỷ lệ $48.1 \%$ ) và 647 người dân (tỷ lệ 51.9\%)), 12 cuộc phỏng vấn sâu, và hai thảo luận nhóm tập trung. Chúng tôi tập trung phân tích, hệ thống những ưu điểm, thành tựu cũng như những nhược điểm, hạn chế trong việc giữ gìn và phát huy phong cách người Đà Lạt hiền hòa, thanh lịch, mến khách bằng việc phân tích các tài liệu thứ cấp, các dữ liệu định tính và định lượng qua quá trình khảo sát thực tế. Bên cạnh sự mô tả phong cách người Đà Lạt, việc phân tích các yếu tố tác động tích cực và tiêu cực đến việc giữ gìn và phát huy phong cách người Đà Lạt cũng được nhấn mạnh. Đồng thời chỉ rõ các chủ thể đã thực hiện trách nhiệm của mình như thế nào đối với việc giữ gìn và phát huy phong cách người Đà Lạt trong quá trình hội nhập và phát triển.

\section{KẾT QUẢ NGHIÊN CỨU VÀ CÁC PHÂN TÍCH}

\subsection{Thực trạng giữ gìn và phát huy phong cách hiền hòa, thanh lịch, mến khách trong quá trình phát triển và hội nhập quốc tế}

2.1.1. Uu điểm, thành tưu giũu gìn và phát huy phong cách người Đà Lạt trong quá trình phát triển và hội nhập quốc tế

Với phương pháp chọn mẫu phân tầng và hệ thống dựa trên sự phân bố cơ cấu dân cư của thành phố Đà Lạt, chúng tôi thu được kết quả nhân khẩu học như sau: Về giới tính người trả lời, có 699 nam giới (tỷ lệ 56.1\%), nữ là 543 (tỷ lệ 43.6\%), giới tính khác là 4 (tỷ lệ $0.3 \%$ ). Độ tuổi từ 31-40 tuổi có 279 người (tỷ lệ $35 \%$ ), 30 tuồi trở xuống có 277 người (tỷ lệ $34.8 \%$ ), từ 41-50 tuổi có 145 người (tỷ lệ $18.2 \%$ ), trên 50 tuổi có 96 người (tỷ lệ 12\%). Đáng chú ý có 449 người không trả lời độ tuổi của mình (tỷ lệ 36\%). Về trình độ học vấn, $56 \%$ người trả lời có trình độ cao đẳng và đại học, $36 \%$ có trình độ THCS và THPT, $2.4 \%$ có trình độ trên đại học, và $5.5 \%$ có trình độ tiểu học. Phần lớn người trả lời đã có vợ/chồng, cụ thể có 733 người (tỷ lệ 58.8\%), có 38\% tình trạng độc thân, $2.2 \%$ ly hôn, $0.9 \%$ góa, và tình trạng khác là $0.2 \%$. Nghề nghiệp của người trả lời: Kinh doanh, buôn bán, và dịch vụ có 336 người (tỷ lệ 33.7\%), lao động giản đơn 168 (tỷ lệ 16.8\%),

\footnotetext{
${ }^{1}$ Nhiệm vụ khoa học công nghệ: Giũ gìn và phát huy phong cách người Đà Lạt "hiền hòa, thanh lịch, mến khách”, Ủy ban Nhân dân thành phố Đà Lạt (Quản lý), Trường Đại học Đà Lạt (Chủ trì), Lê Hồng Phong (Chủ nhiệm), 2018-2020.
} 
làm nông nghiệp 167 (tỷ lệ $16.7 \%$ ), học sinh và sinh viên 141 (tỷ lệ $14.1 \%$ ), còn lại là các ngành nghề khác. Thời gian sinh sống ở Đà Lạt trên 15 năm có 418 người (tỷ lệ $64.6 \%$ ), dưới 5 năm có 108 người (tỷ lệ 16.7\%), từ 11-15 năm có 62 người (tỷ lệ $9.6 \%$ ), và từ 5-10 năm có 59 người (tỷ lệ $9.1 \%$ ). Về khu vực đến của người trả lời, có sự đồng đều của các vùng Miền Trung, Tây Nguyên, và Tây Nam Bộ lần lượt là 24.7\%, 25.8\%, và $29.1 \%$. Số còn lại là miền Đông Nam Bộ $11.4 \%$ và Miền Bắc $9.0 \%$. Trên đây là một số đặc điểm nhân khẩu học của mẫu được khảo sát bằng phương pháp điều tra bằng bảng hỏi. Sở dĩ có một số thông tin về độ tuổi, nghề nghiệp, thời gian sinh sống, khu vực đến của người trả lời có sự khiếm khuyết vì người trả lời không muốn cung cấp thông tin và chúng tôi tôn trọng tính khách quan của quá trình phỏng vấn, hơn nữa mẫu phỏng vấn lớn nên việc thiếu sót thông tin là không thể tránh khỏi.

Ưu điểm và thành tựu của phong cách người Đà Lạt hiền hòa, thanh lịch, mến khách đã được các nhà nghiên cứu, học giả, và giới văn nghệ sĩ như Nguyễn Văn Uông, Nguyễn Hữu Tranh, Nguyễn Văn Cam, Hồ Tấn Trai... thừa nhận, chẳng hạn theo Uông (2018):

Nét tính cách của người Đà Lạt là sự hòa quyện giữa tính thật thà, hồn nhiên của người dân tộc thiểu số bản địa với nét tế nhị, trọng lễ nghĩa của người miền Bắc; Vẻ suy tư, trầm mặc, cẩn trọng của người Thừa Thiên Huế; Tính cần cù cương nghị của người Quảng Nam, Quảng Ngãi; Nét đôn hậu, phóng túng của người phương Nam, cách giao tiếp khéo léo của người Hoa và tinh thần cầu tiến, không cố chấp của người Pháp.

Những đặc trưng trên được biểu hiện rõ nét từ dáng vẻ bên ngoài đến chiều sâu tâm hồn của người dân Đà Lạt. Người Đà Lạt do sống trong một khung cảnh thiên nhiên quanh năm tĩnh lặng, khí hậu mát lạnh, hơn nữa trong quá khứ vùng cao nguyên này hẻo lánh và cách xa các đô thị lớn, ít chịu ảnh hưởng của các cuộc chiến tranh nên cuộc sống người dân êm đềm, người Đà Lạt hiền lành, thật thà, và sớm thích nghi để hòa nhập môi trường sống, với nền kinh tế chủ yếu làm vườn, trồng rau, hoa, quả. Tất cả thể hiện nét hài hòa giữa con người và thiên nhiên tươi đẹp. Sự thanh lịch của người Đà Lạt được thể hiện trong mọi mặt của đời sống từ ăn mặc, nói năng, cho đến cư xử từ trong gia đình, láng giềng, với du khách trong và ngoài nước. Nếu nơi họp chợ bến xe phản ánh rõ nét diện mạo và bộ mặt kinh tế xã hội của một khu vực thì bến xe Đà Lạt yên tĩnh, trật tự, không chèo lái khách. Tiểu thương Đà Lạt trước đây không nói thách và luôn có thái độ vui vẻ hòa nhã với khách hàng.

Người Đà Lạt hiền hòa nhưng không mộc mạc; Chất phác nhưng không cục mịch; Thật thà nhưng không quê mùa; Bán không nói thách, mua không trả giá; Sống không gian dối, lọc lừa; Không thủ đoạn; Không giành giật; Nói năng nhỏ nhẹ...Trong sự thanh lịch của người Đà Lạt có cái cốt cách của người Hà Nội. Người Đà Lạt nói lời hay, ý đẹp mà không khách sáo; Nhẹ nhàng mà không giả tạo; Tài hoa mà không khoe khoang, khoác lác; Hiểu biết mà không ngạo mạn; Giản dị mà không luộm thuộm; Tôn kính mà không cúi luồn. Sự thanh lịch của người Đà Lạt còn có cả sự lịch thiệp, hào hoa, thân thiện từ phong thái của người Pháp (Lê, 2018).

Người Đà Lạt có nguồn gốc từ các vùng miền khác nhau, họ rời bỏ quê hương đến sinh cơ lập nghiệp ở một vùng đất mới, vùng đất vốn rất hoang sơ, núi non trùng điệp 
với khí hậu lạnh lẽo. Những cư dân Đà Lạt đầu tiên hơn ai hết rất mong muốn đón nhận một cách nhiệt tình những người đồng bào của mình đến quần cư làm ăn, sinh sống, phát triển kinh tế, và xây dựng xã hội cộng đồng. Điều đó có thể cắt nghĩa vì sao người Đà Lạt tuy có nhiều nguồn gốc, thành phần khác nhau nhưng luôn luôn đoàn kết, gắn bó, tôn trọng nhau, và cùng nhau xây dựng và phát triển thành phố. Hơn nữa, là thành phố được thiên nhiên ưu đãi, ngay từ đầu xây dựng và cho đến hôm nay, Đà Lạt có điều kiện thuận lợi để phát triển thành một trung tâm du lịch và nghỉ dưỡng đặc thù. Tỉ trọng ngành du lịch và dịch vụ đóng góp ngày càng tăng trong hệ thống cơ cẩu kinh tế, số lượt du khách đến Đà Lạt hàng năm tăng đều. Vì thế, mến khách không chỉ là tình cảm đơn thuần mà còn là lẽ sống, là nguồn sống của người dân Đà Lạt. Kết quả phỏng vấn sâu, thảo luận nhóm tập trung, và phỏng vấn bằng bảng hỏi của chúng tôi cũng có những kết quả tương tự như nêu rõ những ưu điểm của phong cách người Đà Lạt hiền hòa, thanh lịch, mến khách như sau:

Ngoài các yếu tố về khí hậu, phong cảnh... thì mình cũng ấn tượng về con người Đà Lạt. Mình cảm nhận ở đây có sự ấm cúng, gần gũi, đặc biệt là khi tiếp xúc với những người dân địa phương ở đây. Ở họ mình thấy có sự nhẹ nhàng, thư thái, và cũng lãng mạn hơn so với những nơi khác. Mình cũng ấn tượng với cách nói chuyện của những người dân nơi đây với sự nhẹ nhàng, lịch sự, và rất nhiệt tình. Có lần nói chuyện với một bác (chừng ngoài 60 tuổi) là người Huế nhưng sống ở Đà Lạt đã hơn 40 năm. Bác nói chuyện rất lịch sự và cứ mỗi lần mình hỏi việc gì hoặc trước câu trả lời của bác ấy luôn có từ "dạ", từ "vâng" làm mình ngạc nhiên và hơi thẹn vì bác đáng tuổi mẹ của mình. Do đó, mình rất ấn tượng về phong cách của người Đà Lạt và nghĩ rằng đây cũng là một trong những thế mạnh của Đà Lạt để thu hút khách du lịch đến với mình (Nhóm nghiên cứu, 14/6/2019).

Khi nghiên cứu định lượng về thực trạng việc giữ gìn phong cách người Đà Lạt hiện nay, chúng tôi đưa ra năm mức độ giữ gìn phong cách hiền hòa, thanh lịch, mến khách. Kết quả thu được ở các nội dung cụ thể như sau: Cao nhất là mức độ giữ gìn phong cách mến khách, tốt và rất tốt (tỷ lệ $82.7 \%$ ), kế đến là mức độ giữ gìn phong cách hiền hòa, tốt và rất tốt (tỷ lệ $77.7 \%$ ), và mức độ giữ gìn phong cách thanh lịch, tốt và rất tốt (tỷ lệ $74.7 \%$ ). Như vậy có thể khẳng định cả người dân và du khách đều cho rằng người Đà Lạt hiện nay giữ gìn phong cách hiền hòa, thanh lịch, mến khách là tốt và rất tốt (Xem Bảng 1).

Bảng 1. Mức độ giữ gìn phong cách hiền hòa, thanh lịch, mến khách

\begin{tabular}{|c|c|c|c|c|c|c|c|}
\hline \multicolumn{7}{|c|}{ Mức độ giữ gìn phong cách hiền hòa, thanh Mức độ giữ gìn } & \multirow{2}{*}{ Tông } \\
\hline lịch, mến khách & & Rất không tốt & Không tốt & Bình thường & Tốt & Rất tốt & \\
\hline \multirow{2}{*}{ Hiền hòa } & Tần số & 8 & 62 & 207 & 566 & 403 & 1246 \\
\hline & Tỷ lệ (\%) & 0.6 & 5.0 & 16.6 & 45.4 & 32.3 & 100.0 \\
\hline \multirow{2}{*}{ Thanh lịch } & Tần số & 2 & 43 & 270 & 660 & 271 & 1246 \\
\hline & Tỵ lệ (\%) & 0.2 & 3.5 & 21.7 & 53.0 & 21.7 & 100.0 \\
\hline \multirow{2}{*}{ Mến khách } & Tần số & 2 & 40 & 173 & 638 & 393 & 1246 \\
\hline & Tỷ lệ (\%) & 0.2 & 3.2 & 13.9 & 51.2 & 31.5 & 100.0 \\
\hline
\end{tabular}

Nguồn: Số liệu điều tra của Nhóm nghiên cứu, 2019.

Qua phỏng vấn, tất cả người trả lời đều cho rằng phong cách người Đà Lạt là hiền hòa, thanh lịch, mến khách, với các đặc điểm nổi trội nhất: Hiền hòa 610 người trả lời (tỷ lệ 49\%), mến khách 400 người trả lời (tỷ lệ 32.1\%), và thanh lịch 236 người trả lời (tỷ lệ 18.9\%). 
Bảng 2. Đặc điểm nổi trội nhất phản ánh phong cách người Đà Lạt

\begin{tabular}{lll}
\hline Đặc điểm nổi trội nhất phản ánh phong cách người Đà Lạt & Tần số & Tỷ lệ $(\%)$ \\
\hline Hiền hòa & 610 & 49.0 \\
Thanh lịch & 236 & 18.9 \\
Mến khách & 400 & 32.1 \\
Tồng & 1246 & 100.0 \\
\hline
\end{tabular}

Nguồn: Số liệu điều tra của Nhóm nghiên cứu, 2019.

Kết quả phỏng vấn cũng cho biết sự hiền hòa, thanh lịch, mến khách đã đem lại các giá trị cho người dân Đà Lạt như giá trị kinh tế có 940 người trả lời (tỷ lệ 82.2\%) trên số người trả lời; Giá trị văn hóa, xã hội, và môi trường lần lượt là: 767, 614, và 621 với tỷ lệ $67.0 \%, 53.7 \%$, và $54.3 \%$.

Bảng 3. Giữ gìn phong cách hiền hòa, thanh lịch, mến khách

\begin{tabular}{lll}
\hline Giữ gìn phong cách hiền hòa, thanh lịch, mến khách & Tần số & Tỷ lệ (\%) \\
\hline Rất không cần thiết & 9 & 0.7 \\
Không cần thiết & 16 & 1.3 \\
Bình thường & 67 & 5.4 \\
Cần thiết & 548 & 44.0 \\
Rất cần thiết & 606 & 48.6 \\
Tổng & 1246 & 100.0 \\
\hline
\end{tabular}

Nguồn: Số liệu điều tra của Nhóm nghiên cứu, 2019.

Có đến 92.6\% người được phỏng vấn trả lời việc giữ gìn phong cách người Đà Lạt hiền hòa, thanh lịch, mến khách ở mức độ cần thiết và rất cần thiết (Bảng 3 ). Khi được hỏi vì sao việc giữ gìn phong cách hiền hòa, thanh lịch, mến khách là rất cần thiết và cần thiết, kết quả như sau: Vì để giữ gìn bản sắc riêng, đặc trưng của người Đà Lạt có 585 người (tỷ lệ 59.5\%), thu hút khách du lịch có 262 người (tỷ lệ 26.6\%), giữ gìn văn hóa truyền thống có 75 người (7.6\%), và phát triển kinh tế 61 có người (tỷ lẹ̣ $6.2 \%$ ).

\section{Bảng 4. Vì sao rất cần thiết và cần thiết trong giữ gìn phong cách hiền hòa, thanh lịch, mến khách của người Đà Lạt}

\begin{tabular}{lll}
\hline Lý do rất cần thiết và cần thiết trong giữ gìn phong cách hiền hòa, thanh lịch, mến khách & Tần số Tỷ lệ $(\%)$ \\
\hline Bản sắc riêng, đặc trưng của người Đà Lạt & 585 & 59.5 \\
Giữ gìn văn hóa truyền thống & 75 & 7.6 \\
Phát triển kinh tế & 61 & 6.2 \\
Thu hút khách du lịch & 262 & 26.6 \\
Tồng & 983 & 100.0 \\
Missing & 171 & 14.8 \\
\hline
\end{tabular}

Nguồn: Số liệu điều tra của Nhóm nghiên cứu, 2019.

Cả người dân và du khách đều có những việc đã làm để giữ gìn và phát huy phong cách hiền hòa, thanh lịch, mến khách của người Đà Lạt như: Tôi không vứt rác bừa bãi, tần số 905 (tỷ lệ cao nhất 73.2\%); Tôi cư xử hòa nhã nhẹ nhàng với những người xung quanh, tần số 895 (tỷ lệ $72.4 \%$ ); Tôi sẵn lòng giúp đỡ người khác khi cần thiết, tần số 859 (tỷ lệ 69.4\%); Tôi tham gia giao thông an toàn và văn minh, tần số 674 (tỷ lệ 54.5\%); Tôi thường xuyên tham gia quét dọn cổng, ngõ nhà mình, tần số 649 (tỷ lệ 52.5\%); Tôi nhắc nhở con cháu trong giao tiếp và ứng xử văn minh hòa nhã với mọi người, tần số 483 (tỷ 
lệ 39\%); Gia đình tôi tham gia hội họp tổ dân phố định kỳ, tần số 410 (tỷ lệ $33.1 \%$ ); Khác, tần số 2 (tỷ lệ 2\%) (Bảng 5).

\section{Bảng 5. Các việc đã làm để giữ gìn và phát huy phong cách hiền hòa, thanh lịch, mến khách của người Đà Lạt}

\begin{tabular}{|c|c|c|}
\hline $\begin{array}{l}\text { Các việc đã làm để giữ gìn và phát huy phong cách hiền hòa, thanh lịch, mến khách của } \\
\text { người Đà Lạt }(\mathrm{n}=1246)\end{array}$ & Tần số & $\begin{array}{l}\text { Tỷ lệ } \\
(\%)\end{array}$ \\
\hline 1. Tôi không vứt rác bừa bãi & 905 & 73.2 \\
\hline 2. Tôi cư xử hòa nhã nhẹ nhàng với những người xung quanh & 895 & 72.4 \\
\hline 3. Tôi sẵn lòng giúp đỡ người khác khi cần thiết & 859 & 69.4 \\
\hline 4. Tôi thường xuyên tham gia quét dọn cổng, ngõ nhà mình & 649 & 52.5 \\
\hline 5 Tôi tham gia giao thông an toàn và văn minh & 674 & 54.5 \\
\hline 6. Gia đình tôi sinh sống không ồn ào, làm ảnh hưởng hàng xóm xung quanh & 630 & 50.9 \\
\hline 7. Gia đình tôi tham gia hội họp tổ dân phố định kỳ & 410 & 33.1 \\
\hline 8. Tôi nhắc nhở con cháu trong giao tiếp, ứng xử văn minh hòa nhã với mọi người & 483 & 39.0 \\
\hline 9. Khác & 2 & 0.2 \\
\hline
\end{tabular}

\section{Nguồn: Số liệu điều tra của Nhóm nghiên cứu, 2019.}

Ở cấp độ cá nhân và gia đình, để giữ gìn và phát huy phong cách hiền hòa, thanh lịch, mến khách thì người Đà Lạt ý thức rõ việc đã và sẽ làm là thực hiện các nghĩa vụ và trách nhiệm của một công dân thành phố như: Không vứt rác bừa bãi, cư xử hòa nhã với những người xung quanh, sẵn lòng giúp đỡ người khác khi cần thiết, thường xuyên tham gia quét dọn cổng, ngõ nhà mình, tham gia giao thông an toàn và văn minh, sống không ồn ào, làm ảnh hưởng đến hàng xóm xung quanh, tham gia họp tổ dân phố định kỳ, và nhắc nhở con cháu trong giao tiếp, ứng xử văn minh, hòa nhã với mọi người. Ở cấp độ trung mô và vĩ mô, các kết quả các cuộc thảo luận nhóm tập trung chúng tôi cũng ghi nhận những giải pháp để giữ gìn và phát huy phong cách người Đà Lạt hiền hòa, thanh lịch, mến khách.

\section{Bảng 6. Yếu tố tác động tích cực đến việc giữ gìn phong cách hiền hòa, thanh lịch, mến khách}

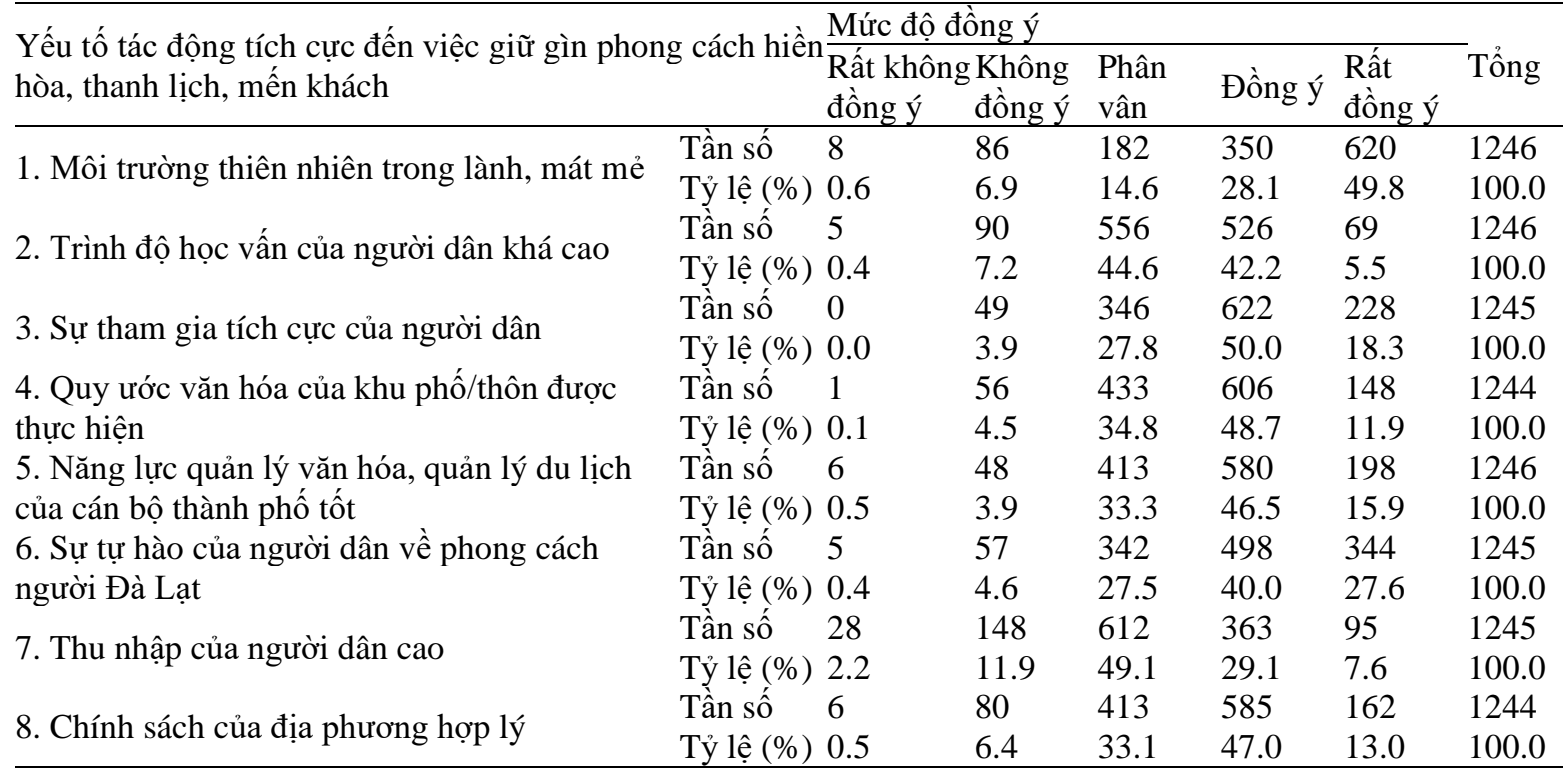

Nguồn: Số liệu điều tra của Nhóm nghiên cứu, 2019. 
Kết quả điều tra (Bảng 6) cho thấy môi trường thiên nhiên trong lành và mát mẻ là yếu tố tác động tích cực nhất đến việc giữ gìn phong cách hiền hòa, thanh lịch, mến khách với mức độ đồng ý và rất đồng ý cao nhất (tỷ lệ $71.6 \%$ ) số người trả lời; Kế đến là sự tham gia tích cực của người dân (tỷ lệ $68.3 \%$ ); Sự tự hào của người dân về phong cách người Đà Lạt (tỷ lệ 67.6\%); Năng lực quản lý văn hóa và quản lý du lịch của cán bộ thành phố tốt (tỷ lệ 62.4\%); Quy ước văn hóa của khu phố/thôn được thực hiện (tỷ lệ 60.6\%); Chính sách của địa phương hợp lý (tỷ lệ 50.0\%); Trình độ học vấn của người dân khá cao (tỷ lệ 47.7\%); Thấp nhất trong các yếu tố tác động tích cực đến việc giữ gìn phong cách người Đà Lạt hiền hòa, thanh lịch, mến khách là thu nhập của người dân cao (tỷ lệ 36.7\%).

Kết quả phỏng vấn bằng bảng hỏi 599 du khách đến Đà Lạt trong năm năm trở lại đây cho được những kết quả như Bảng 7. Có thể nói, lượt khách đến Đà Lạt tương đối ổn định, từ 1-3 lần (tỷ lệ cao nhất 70.6\%), tiếp đến từ 4-6 lần, từ 7-9 lần, và trên 10 lần lần lượt theo tỷ lệ $20.9 \%, 5.0 \%$, và $3.5 \%$.

\section{Bảng 7. Số lần đến Đà Lạt trong 5 năm trở lại đây}

\begin{tabular}{lll}
\hline Số lần đến Đà Lạt trong năm năm trở lại đây & Tần số & Tỷ lệ (\%) \\
\hline Từ 1-3 lần & 423 & 70.6 \\
Từ 4-6 lần & 125 & 20.9 \\
Từ 7-9 lần & 30 & 5.0 \\
Từ 10 lần trở lên & 21 & 3.5 \\
Tổng & 599 & 100.0 \\
\hline
\end{tabular}

Nguồn: Số liệu điều tra của Nhóm nghiên cứu, 2019.

Bảng 8 trình bày một số chỉ tiêu kế hoạch phát triển sự nghiệp văn hóa-xã hội năm 2020 trích trong báo cáo tổng kết của Sở Văn hóa Thể thao và Du lịch tỉnh Lâm Đồng năm 2019; Phương hướng và nhiệm vụ năm 2020.

Bảng 8. Chỉ tiêu kế hoạch phát triển sự nghiệp văn hóa-xã hội năm 2020

\begin{tabular}{|c|c|c|c|c|c|}
\hline STT & Chỉ tiêu & ĐVT & КН 2019 & Thực hiện năm 2019 & $\begin{array}{l}\text { \% so với kế } \\
\text { hoạch năm }\end{array}$ \\
\hline \multirow{4}{*}{1} & DU LICH & \multirow{4}{*}{ 1,000 khách } & & & \\
\hline & Tổng lượt khách & & 7,150 & 7,160 & 100.1 \\
\hline & - Khách nội địa & & 6,617 & 6,627 & 100.2 \\
\hline & - Khách quốc tế & & 533 & 533 & 100.0 \\
\hline 2 & $\begin{array}{l}\text { Tống lượt khách du lịch } \\
\text { qua đăng ký lưu trú }\end{array}$ & 1,000 khách & 4,850 & 4,860 & 100.2 \\
\hline 3 & Ngày lưu trú bình quân & Ngày & 2.2 & 2.1 & 95.0 \\
\hline
\end{tabular}

Nguồn: Sở Văn hóa Thể thao và Du lịch tỉnh Lâm Đồng, 2020.

Nhìn vào kết quả Bảng 8 , chúng ta có thể thấy hầu hết các chỉ tiêu đưa ra đều đạt và vượt phần trăm so với kế hoạch, duy chỉ có mức độ lưu trú chưa đạt được. Điều này gợi mở cho việc nâng cao chất lượng phục vụ để giữ chân du khách khi họ đến Đà Lạt.Du khách đến Đà Lạt bởi lý do cảnh quan của Đà Lạt tươi đẹp và dễ chịu (tỷ lệ cao nhất $77.0 \%$ ), kế đến là khí hậu mát mẻ và trong lành (tỷ lệ 70.7\%), người Đà Lạt hiền hòa, thanh lịch, mến khách (tỷ lệ 61.3\%). Hai lý do có tỷ lệ thấp nhất là ẩm thực Đà Lạ ngon và giá cả hợp lý (tỷ lệ $44.7 \%$ ) và dịch vụ du lịch chất lượng chiếm tỷ lệ thấp nhất (tỷ lệ 26.7\%) (Bảng 9). 
Bảng 9. Lý do thích đến Đà Lạt

\begin{tabular}{lll}
\hline Lý do thích đến Đà Lạt $(\mathrm{n}=599)$ & Tần số & Tỷ lệ $(\%)$ \\
\hline Người Đà Lạt hiền hòa, thanh lịch, mến khách & 362 & 61.3 \\
Cảnh quan của Đà Lạt tươi đẹp và dễ chịu & 455 & 77.0 \\
Khí hậu mát mẻ và trong lành & 418 & 70.7 \\
Ấm thực Đà Lạt ngon và giá cả hợp lý & 264 & 44.7 \\
Dịch vụ du lịch chất lượng & 158 & 26.7 \\
\hline
\end{tabular}

Nguồn: Số liệu điều tra của Nhóm nghiên cứu, 2019.

Qua số liệu Bảng 9 có thể nhận định việc khách du lịch đến Đà Lạt là do cảnh quan, khí hậu và con người Đà Lạt. Đà Lạt là miền đất hiếm có, cảnh quan, khí hậu là nguồn tài nguyên thiên nhiên ban tặng, cần phải trân quý và giữ gìn. Sự xuống cấp về cơ sở vật chất còn có thể khắc phục được chứ sự xuống cấp về khí hậu và cảnh quan do con người gây ra thì khó mà khắc phục. Người Đà Lạt vốn hồn nhiên, thật thà, giàu tính thiện, lòng nhân ái, có sự nhất quán giữa lời nói và hành vi cư xử. Đà Lạt là miền đất của cảnh đẹp và của người hiền. Sự kết hợp của khí hậu, cảnh quan, con người Đà Lạt quyết định lý do du khách tìm về Đà Lạt. Dữ liệu của Bảng 9 cũng cho chúng ta lưu ý đến yếu tố ầm thực ngon, giá cả hợp lý, và dịch vụ du lịch có chất lượng cần được chú trọng nhiều hơn nữa, bởi du khách đến Đà Lạt ngoài việc thưởng ngoạn cảnh quan, môi trường, và khí hậu họ còn phải được phục vụ dịch vụ du lịch có chất lượng, được thưởng thức các món ăn ngon và giá cả hợp lý. Có làm được điều này, du lịch Đà Lạt mới phát triển bền vững. Khi tiến hành phỏng vấn sâu người dân, chúng tôi có thu được một ý kiến đáng lưu ý:

Đà Lạt không cần phải phát triển các khu công nghiệp, xây dựng nhà máy, xí nghiệp rồi tập trung nhân công trên diện rộng, phát triển sản xuất như các đô thị công nghiệp. Đà Lạt chỉ cần xây dựng một thành phố của du lịch mà khắp các con đường đều có hoa; Nhiều khu du lịch vui chơi giải trí đẹp, thu hút; Khách sạn sạch sẽ, âm cúng, tiện nghi và các món ăn ngon phục vụ mọi đối tượng. Bởi lẽ mọi du khách đều có nhu cầu thưởng thưởng cảnh đẹp, vui chơi, ăn uống và nghỉ ngơi trong hành trình của mình (Nhóm nghiên cứu, 17/6/2019).

Người Đà Lạt xưa và nay đều khiến du khách hài lòng bởi lòng nhiệt thành, hòa đồng, thân thiện. Đà Lạt cũng là nơi có khí hậu mát mẻ, hiền hòa, nhiều cảnh đẹp, kiến trúc độc đáo, ẩm thực ngon, được trình bày trong Bảng 10.

\section{Bảng 10. Điều hài lòng nhất khi đến Đà Lạt}

\begin{tabular}{lll}
\hline Điều hài lòng nhất khi đến Đà Lạt $(\mathrm{n}=357)$ & Tần số & Tỷ lệ $(\%)$ \\
\hline Con người nhiệt tình, hòa đồng, và thân thiện & 219 & 61.3 \\
Khí hậu mát mé, hiền hòa. Nhiều cảnh đẹp. Kiến trúc độc đáo. Ẩm thực ngon. 138 & 38.7 \\
\hline
\end{tabular}

Nguồn: Số liệu điều tra của Nhóm nghiên cứu, 2019.

Theo tôi, mức độ giữ gìn phong cách người Đà Lạt hiện nay là khá tốt. Tuy nhiên, chủ yếu ở những người lớn tuổi mới giữ gìn được cốt cách của người Đà Lạt. Trước đây, nghỉ dưỡng là người ta ở lâu và sinh hoạt luôn ở đây vào buổi chiều người ta đi dạo tiếp xúc với cư dân, còn bây giờ họ đi ồ ạt, tạo nên một số người tranh thủ cơ hội chộp giật với khách du lịch ảnh hưởng đến phong cách người Đà Lạt (Nhóm nghiên cứu, 2019). 
Theo tôi, hiện nay, phong cách của người Đà Lạt vẫn hiền hòa, thanh lịch, mến khách. Trong đó, chỉ có một số ít cư dân vì một số lý do như mới từ nơi khác đến hay do làm ăn, mưu sinh... mà họ đã vô tình phá vỡ đi hình ảnh vốn có về phong cách của người Đà Lạt, chứ theo tôi, những người dân sinh sống tại Đà Lạt từ trước đến nay thì hầu như phong cách của họ không có gì thay đổi. Phong cách của họ đã được hình thành và chi phối bởi nhiều yếu tố về điều kiện tự nhiên, văn hóa, và xã hội nơi đây, và không chỉ riêng họ mà họ còn truyền dạy những phẩm chất đó cho con họ, cháu họ nên nó không dễ bị thay đổi (Nhóm nghiên cứu, 02/7/2019).

\subsubsection{Nhược điểm, hạn chế trong việc giũ gìn và phát huy phong cách người Đà Lạt trong quá trình phát triển và hội nhập quốc tế.}

Trước thế kỷ 19, Đà Lạt là vùng đất cư trú lâu đời của người đồng bào dân tộc thiểu số Lạch. Người Pháp, trong quá trình xâm lược các nước thuộc địa Đông Dương, mong muốn tìm kiếm một vùng đất nghỉ dưỡng cho công chức và binh lính Pháp với khí hậu ôn đới tương tự với chính nước Pháp ở Châu Âu, đã khám phá ra Đà Lạt mà công lao ây được ghi nhận thuộc về bác sĩ người Pháp gốc Thụy Sĩ Alexandre Yersin. Người Kinh đồng thời cùng với người Pháp sau đó đến định cư và sinh sống dựng xây thành phố này cho đến nay gần được 130 năm (1893-2020). Trong quá trình dựng xây và phát triển, thành phố này được đặt thêm nhiều danh xưng như: Thành phố Ngàn hoa, thành phố Mộng mơ, thành phố Tình yêu, Xứ hoa Đào..."Đà Lạt là tiên cảnh giữa trần ai...ai cũng biết đấy là cách nói ẩn dụ, tức là nói ngoa, thế nhưng những người đến Đà Lạt nói như vậy, người ở Đà Lạt lâu cũng nói như vậy, và tôi, người đến sau chưa hiểu sâu về Đà Lạt cũng cảm nhận như vậy...” (Hồ, 1997). Bên cạnh những ý kiến ca ngợi về cái hay, cái đẹp của người Đà Lạt hiền hòa, thanh lịch, mến khách thì người Đà Lạt cũng bộc lộ những mặt hạn chế và nhược điểm. Hai loại ý kiến khác nhau đều có cơ sở thực tế và đều mang ý nghĩa tích cực. Người phàn nàn hay kêu ca vì mong muốn ngăn chặn tình trạng xuống cấp. Người ca ngợi Đà Lạt không tiếc lời vì cảm nhận sự tuyệt vời về cảnh đẹp, người hiền, về sự thân thiện, mến khách của người Đà Lạt. Cần phải khẳng định rằng, việc giữ gìn và phát huy phong cách người Đà Lạt hiền hòa, thanh lịch, mến khách là vì mục đích nhân sinh, là để mưu cầu sự phát triển kinh tế, chính trị, xã hội, văn hóa bền vững cho hôm nay và các thế hệ con cháu mai sau, để không có thể hổ thẹn với các bậc tiền nhânnhững người đã chọn mảnh đất lành làm nơi an lạc. Vì thế, việc nhận ra những khiếm khuyểt, hạn chế trong việc giữ gìn và phát huy phong cách người Đà Lạt hiền hòa, thanh lịch, mến khách là việc làm có ý nghĩa thực tiê̂n, tích cực nhằm phát huy vai trò chủ thểngười Đà Lạt trong quá trình hội nhập và phát triển.

Mặc dù hầu hết người trả lời thừa nhận việc giữ gìn phong cách người Đà Lạt là tốt và rất tốt, nhưng bên cạnh đó cũng có người cho rằng việc giữ gìn phong cách người Đà Lạt không tốt và rất không tốt bởi các lý do và mức độ như Bảng 11.

Có 90 câu trả lời về việc giữ gìn phong cách người Đà Lạt hiện nay không tốt và rất không tốt là do: Người dân mải làm ăn, lo việc riêng của mình và gia đình họ; Do người dân nghĩ đó không phải là việc của mình; và Do người dân không được tuyên truyền về ý thức trách nhiệm cần giữ gìn. 
Bảng 11. Lý do giữ gìn "Rất không tốt"/“Không tốt"

\begin{tabular}{|c|c|c|c|c|c|c|c|}
\hline \multirow{2}{*}{\multicolumn{2}{|c|}{ Lý do giữ gìn "Rất không tốt"/“Không tốt” }} & \multicolumn{5}{|c|}{ Mức đô giữ gìn } & \multirow[b]{2}{*}{ Tổng } \\
\hline & & $\begin{array}{l}\text { Rất không } \\
\text { đồng ý }\end{array}$ & $\begin{array}{l}\text { Khồng } \\
\text { đồng ý }\end{array}$ & Phân vân & Đồng ý & $\begin{array}{l}\text { Rất } \\
\text { đồng ý }\end{array}$ & \\
\hline 1. Do người dân mải làm ăn, lo việc riêng & Tần số & 4 & 30 & 34 & 17 & 5 & 90 \\
\hline của $m$ & Tỷ lệ (\%) & 4.4 & 33.3 & 37.8 & 18.9 & 5.6 & 100.0 \\
\hline rời dân nghĩ đó không phải là & Tần số & 7 & 19 & 44 & 17 & 3 & 90 \\
\hline việc c & Tỷ 1 & 7.8 & 21.1 & 48.9 & 18.9 & 3.3 & 100.0 \\
\hline 3. Người dân nghĩ đó là việc của chính & Tần & 6 & 22 & 29 & 22 & 11 & 90 \\
\hline quyền & Tỷ lệ (\%) & 6.7 & 24.4 & 32.2 & 24.4 & 12.2 & 100.0 \\
\hline 4. Ngườ & Tần số & 4 & 13 & 33 & 27 & 13 & 90 \\
\hline ý thức trách nhiệm cần giữ gìn & Tỷ lệ (\%) & 4.4 & 14.4 & 36.7 & 30.0 & 14.4 & 100.0 \\
\hline
\end{tabular}

Nguồn: Số liệu điều tra của Nhóm nghiên cứu, 2019.

Kết quả phỏng vấn sâu và thảo luận nhóm tập trung cũng cho được những kết quả "lưỡng phân" như việc đồng ý/không đồng ý với phong cách hiền hòa, thanh lịch, mến khách của người Đà Lạt như:

Theo tôi, việc giữ gìn phong cách hiền hòa, thanh lịch, mến khách của người Đà Lạt hiện nay là chưa thực sự tốt. Bởi vì, bây giờ khi ra đường tôi vẫn thấy những hiện tượng một bộ phận thế hệ trẻ vẫn chạy xe ẩu, không nhường đường cho người lớn tuổi. Trước đây, đặc trưng dễ nhận thấy của người Đà Lạt khi tham gia giao thông là thường nhường nhịn lẫn nhau... Chẳng hạn, nếu như có một ai đó vượt qua trước, họ sẽ mở lời "xin lỗi” và "cảm ơn" để làm nhẹ đi một lời chê trách, hay người nào đó thiếu ý thức khi tham gia giao thông, người Đà Lạt thường đặt câu hỏi "con nhà ai vậy”... Những lời nói và cử chỉ ây được các gia đình giáo dục con cái từ khi còn nhỏ tuổi (Nhóm nghiên cứu, 14/6/2019).

\section{Bảng 12. Điều khó chịu nhất khi đến Đà Lạt}

\begin{tabular}{lll}
\hline Điều khó chịu nhất khi đến Đà Lạt $(\mathrm{n}=420)$ & Tần số & Tỷ lệ $(\%)$ \\
\hline Bán hàng rong nhiều & 2 & 0.5 \\
Chặt chém du khách & 103 & 24.5 \\
Chèo kéo khách du lịch & 20 & 4.8 \\
Đường khó tìm & 2 & 0.5 \\
Hết phòng dịp lễ & 1 & 0.2 \\
Hiện tượng cò Đà Lạt & 7 & 1.7 \\
Không có & 194 & 46.2 \\
Kiến trúc truyền thống bị phá hủy & 3 & 0.7 \\
Nói tục, chửi thề & 4 & 1.0 \\
Ô nhiềm môi trường Hồ Xuân Hương & 6 & 1.4 \\
Phá rừng & 3 & 0.7 \\
Phân biệt đối xử giữa dân và khách & 1 & 0.2 \\
Phát triển chưa bền vững & 2 & 0.5 \\
Quá tải hạ tầng giao thông & 48 & 11.4 \\
Thái độ thiếu lịch sự & 20 & 4.8 \\
Tỷ lệ dân nhập cư còn cao & 2 & 0.5 \\
Xả rác bừa bãi khi có lễ hội & 2 & 0.5 \\
\hline
\end{tabular}

Nguồn: Số liệu điều tra của Nhóm nghiên cứu, 2019. 
Khi hỏi điều gì khó chịu nhất khi đến Đà Lạt, du khách hầu hết trả lời là không có, tần số tương đối là 194/420 người (tỷ lệ cao nhất 46.2\%) như bảng số liệu sau. Kế tiếp là có tình trạng chặt chém du khách tần số 103 (tỷ lệ $24.5 \%$ ). Đáng lưu ý trong nghiên cứu này của chúng tôi có yếu tố quá tải về hạ tầng giao thông, tần số 48 (tỷ lệ 11.4\%). Mấy năm trở lại đây vấn đề kẹt xe, tắc đường có chiều hướng gia tăng khi lượng khách đến Đà Lạt nhiều trong những dịp lễ hay dị̣ tết. Theo thông tin chúng tôi được biết, chính quyền thành phố đã có những giải pháp nhằm khắc phục tình trạng này trong thời gian trước mắt cũng như có chiến lược lâu dài cho sự phát triển hạ tầng giao thông của thành phố, ví dụ như nâng cấp các tuyến đường, điều phối giao thông, mở rộng các bến xe, bãi đỗ...

\section{Bảng 13. Yếu tố tác động tiêu cực đến giữ gìn phong cách hiền hòa, thanh lịch, mến khách}

\begin{tabular}{|c|c|c|c|c|c|c|c|}
\hline \multirow{2}{*}{\multicolumn{2}{|c|}{$\begin{array}{l}\text { Yếu tố tác động tiêu cực đến việc giữ gìn } \\
\text { phong cách hiền hòa, thanh lịch, mến khách }\end{array}$}} & \multicolumn{5}{|c|}{ Mức độ đồng ý } & \multirow[t]{2}{*}{ Tổng } \\
\hline & & $\begin{array}{l}\text { Rất không } \\
\text { đồng ý }\end{array}$ & $\begin{array}{l}\text { Không } \\
\text { đồng ý }\end{array}$ & Phân vân & Đồng ý & $\begin{array}{l}\text { Rất } \\
\text { đồng ý }\end{array}$ & \\
\hline \multirow{8}{*}{$\begin{array}{l}\text { 1. Dân số tăng nhanh, sự phức tạp } \\
\text { của dân cư } \\
\text { 2. Tư tưởng chộp giật của người } \\
\text { dân làm kinh doanh, du lịch } \\
\text { 3. Ý thức thiếu tôn trợn môi } \\
\text { trường địa phương của du khách } \\
\text { 4. Chính sách địa phương chưa } \\
\text { phù hợp }\end{array}$} & Tần số & 37 & 131 & 444 & 424 & 210 & 1246 \\
\hline & Tỷ lệ (\%) & 3.0 & 10.5 & 35.6 & 34.0 & 16.9 & 100.0 \\
\hline & Tần số & 40 & 141 & 474 & 411 & 180 & 1246 \\
\hline & Tỷ lệ (\%) & 3.2 & 11.3 & 38.0 & 33.0 & 14.4 & 100.0 \\
\hline & Tần số & 61 & 118 & 411 & 437 & 219 & 1246 \\
\hline & Tỷ lệ (\%) & 4.9 & 9.5 & 33.0 & 35.1 & 17.6 & 100.0 \\
\hline & Tần số & 55 & 199 & 459 & 360 & 171 & 1244 \\
\hline & Tỷ lệ (\%) & 4.4 & 16.0 & 36.9 & 28.9 & 13.7 & 100.0 \\
\hline \multirow{2}{*}{ 5. Năng lực quản lý yếu kém } & Tần số & 66 & 179 & 492 & 334 & 173 & 1244 \\
\hline & Tỷ lệ (\%) & 5.3 & 14.4 & 39.5 & 26.8 & 13.9 & 100.0 \\
\hline
\end{tabular}

Nguồn: Số liệu điều tra của Nhóm nghiên cứu, 2019.

Kết quả khảo sát bằng bảng hỏi đã cho ra những kết quả về các yếu tố tác động tiêu cực đến việc giữ gìn phong cách hiền hóa, thanh lịch, mến khách như sau: Dân số tăng nhanh sự phức tạp của dân cư, mức độ đồng ý và rất đồng ý có tỷ lệ $50.9 \%$; Tư tưởng chộp giật của người dân làm kinh doanh, du lịch, mức độ đồng ý và rất đồng ý có tỷ lệ $47.4 \%$; Ý thức thiếu tôn trọng môi trường địa phương của du khách, mức độ đồng ý và rất đồng ý có tỷ lệ $52.7 \%$; Chính sách địa phương chưa phù hợp, mức độ đồng ý và rất đồng ý có tỷ lệ $42.6 \%$; và Năng lực quản lý yếu kém, mức độ đồng ý và rất đồng ý có tỷ lệ 40.7\%.

Như vậy, yếu tố tác động tiêu cực nhiều nhất theo người trả lời đó là dân số tăng nhanh và sự phức tạp của dân cư. Đây là biến số khó có thể kiểm soát bởi xu hướng của quá trình công nghiệp hóa, hiện đại hóa đem lại, và quy luật nước chảy về chỗ trũng, nơi nào thuận lợi, và dễ làm ăn sinh sống là người dân đến. Yếu tố tư tưởng chộp giật của người dân làm kinh doanh du lịch và ý thức thiếu tôn trọng môi trường địa phương của du khách là biến số quan trong thuộc về người dân địa phương và du khách, là hai chủ thể quan trọng tác động tiêu cực đến việc giữ gìn phong cách hiền hòa, thanh lịch, mến khách. Hai yếu tố còn lại đó là chính sách địa phương chưa hợp lý và năng lực quản lý yếu kém. Theo chúng tôi, đây là chủ thể quan trọng nhất, quyết định đến việc giữ gìn phong cách người Đà Lạt, bởi chính sách và năng lực quản lý của cơ quan công quyền, là chủ thể lãnh đạo toàn diện, ảnh hưởng đến mọi mặt của việc giữ gìn và phát huy phong cách người Đà Lạt trong quá trình hội nhập và phát triển. Trong các thảo luận nhóm định tính khác, chúng tôi cũng thu được kết quả tương tự "Yếu tố cản trở là do dân số tăng 
nhanh cộng với tư tưởng chộp giật của một bộ phận những người dân làm kinh doanh và du lịch. Ngoài ra, cách quản lý của mình là tình không ra tình, lý không ra lý, cách quản lý không rạch ròi, cách quản lý như cho nhập cư ồ ạt và phân lô bán đất một cách thiếu kiểm soát" (Nhóm nghiên cứu, 16/6/2019).

\subsection{Nguyên nhân của những thành tựu và hạn chế trong việc giữ gìn và phát huy phong cách người Đà Lạt}

Người Đà Lạt hiền hòa, thanh lịch, mến khách là nói đến phong cách của người Việt Nam sống trên thành phố Cao Nguyên này, nhưng do đặc điểm độc đáo của thiên nhiên, địa hình, môi trường cảnh quan, khí hậu, yếu tố xã hội, kinh tế, và yếu tố tư tưởng và tinh thần, nên người Đà Lạt có những nét đặc trưng trên. Trong quá trình thu thập dữ liệu phục vụ nghiên cứu, chúng tôi nhận thấy ẩn sau nhiều câu chuyện về niềm tự hào người Đà Lạt hiền hòa, thanh lịch, mến khách thì cũng có sự nuối tiếc, hoài niệm, buồn thương nhớ ngày xưa. Phong cách, lối sống của người Đà Lạt ngày nay hiện đại rồi và không còn lạc hậu nữa. Trong quá trình thu thập và phân tích dữ liệu, chúng tôi suy nghĩ về hai chiều tâm trạng trái ngược. Điều gì khiến người Đà Lạt một mặt, luôn tự hào về sự hiền hòa, thanh lịch, mến khách, thay da, đổi thịt theo hướng hiện đại hơn, công nghệ hơn, mặt khác, lại tiếc nuối, buồn phiền trước sự phai nhạt của truyền thống? Liệu người Đà Lạt có cầu toàn hay kỳ vọng quá nhiều vào sự ổn định và quan ngại trước sự biến chuyển của phong cách người Đà Lạt hôm nay? Liệu sự mâu thuẫn ấy có một chiều cảm xúc bị ngộ nhận hay phản ánh thực tế "lưỡng phân", nơi mảnh đất được mệnh danh là "Thành phố mộng mơ" và hiện nay là "Thành phố của du lịch". Việc tập trung phân tích, diễn giải, và thảo luận về phong cách người Đà Lạt hiền hòa, thanh lịch, mến khách được xem xét dưới nhiều góc nhìn. Những phân tích sẽ chỉ rõ ra mối liên hệ giữa diễn ngôn về khái niệm hiền hòa, thanh lịch, mến khách từ trong giới tri thức, học giả, nhà nghiên cứu khoa học đến cách hiểu và tiếp nhận của người dân sống tại thành phố Đà Lạt, cũng như khách du lịch đến từ trong và ngoài nước. Thay vì nhìn nhận tính "hiện đại" và "đương thời” hiện nay như một hệ giá trị cố định và mang tính tiến hóa, cần phân tích chỉ ra mối liên hệ với truyền thống. Hiện đại không phải lúc nào cũng loại trừ, đối lập truyền thống. Trái lại, nó kế thừa và phát triển trên nền tảng truyền thống ở chiều cạnh khác trong quá trình phát triển và hội nhập quốc tế. Ngày nay, thành phố Đà Lạt với thực trạng về môi trường cảnh quan thiên nhiên, địa hình khí hậu, thời tiết, kiến trúc xây dựng, dân số, các thành phần dân cư, đặc biệt là số lượng du khách đến Đà Lạt đã làm bức tranh Đà Lạt thêm nhiều sắc thái sinh động nhưng cũng không kém phần ồn ào, náo nhiệt, và phức tạp. Việc nghiên cứu và nhận diện những nét đặc thù, nguyên nhân của những thành tựu, khuyết điểm, nhằm phát huy về phong cách và lối sống tốt đẹp của người Đà Lạt càng trở nên cấp thiết, có ý nghĩa lý luận và thực tiễn quan trọng trong chiến lược phát triển thành phố.

\subsubsection{Nguyên nhân của những thành tưu trong giũu gìn và phát huy phong cách người Đà Lạt}

Như đã phân tích ở phần trên, Đà Lạt là viên ngọc quý của Việt Nam, là một thành phố nổi tiếng trên thế giới từ hơn 100 năm về trước. Vùng đất này được thiên nhiên ban tặng cho một địa hình, thổ nhưỡng, khí hậu tươi mát quanh năm, đất đai màu mỡ, sản vật phong phú. Đây là nguyên nhân cơ sở, đầu tiên và quan trọng của những thành tựu trong 
việc hình thành, giữ gìn, và phát huy phong cách người Đà Lạt. Quả thật, với độ cao trung bình so với mặt biển và được rừng thông bao bọc, khí hậu Đà Lạt mang đặc tính của miền ôn đới. Nhiệt độ trung bình từ $18^{\circ} \mathrm{C}$ đến $21^{\circ} \mathrm{C}$, nhiệt độ cao nhất chưa bao giờ quá $30^{\circ} \mathrm{C}$, thấp nhất không dưới $5{ }^{\circ} \mathrm{C}$ và không bao giờ có bão, chỉ có gió lớn do ảnh hưởng bão từ biển thổi vào vì sườn đông không có núi che chắn. Đà Lạt là vùng đất cao nguyên, khí hậu quanh năm mát mẻ nếu không muốn nói lạnh lẽo. Vì thế trang phục kín đáo, đảm bảo âm áp là nhu cầu tự nhiên của con người Đà Lạt. Cách ăn mặt kín đáo, nhưng đàng hoàng, và trang nhã làm cho người Đà Lạt có nét trầm tư và thanh lịch. Không những trong trang phục, ăn, và ở của người Đà Lạt cũng mang vẻ kín đáo. Nhà của Đà Lạt, dù là biệt thự hay nhà bình dân cũng ấm cúng, không thoáng gió như xứ nóng. Mọi sinh hoạt chủ yếu chỉ diễn ra trong phạm vi ngôi nhà.

Khí hậu mát mẻ ảnh hưởng đến thể chất con người, người Đà Lạt, nhất là phụ nữ và trẻ em có vẻ đẹp tự nhiên, đôi má ửng hồng, nét đẹp trầm trầm, kín đáo, và hơi e thẹn nhưng rất tự tin. Đà Lạt với một không gian xanh, từ cảnh quan thiên nhiên, cây, cỏ đến con suối, dòng nước... Môi trường sống thanh bình, nhịp sống không xô bồ, khẩn trương, hay náo nhiệt như các thành phố khác đã làm cho con người cảm giác yên lành, bình thản, và dễ chịu thích hợp cho các loại hình lao động trí óc và những ngành nghề có độ yêu cầu chính xác và tinh vi. Bởi thiên nhiên bao quanh Đà Lạt "thành phố trong rừng, rừng trong thành phố", người Đà Lạt tiếp xúc với thiên nhiên, cây cỏ thường xuyên nên tính chất thật thà, chất phác, hiền lành hơn, đôn hậu hơn.

Nếu con người là tổng hòa các mối quan hệ tự nhiên và xã hội thì yếu tố thiên nhiên dự phần quan trọng hình thành phong cách con người sinh trưởng tại xứ sở "muôn hoa, ngàn cây, núi non trùng điệp này". Đã là con người ai cũng có nhu cầu được thoải mái, dễ chịu, không bị hoàn cảnh làm căng thẳng tinh thần. Hoạt động trí óc, hành vi ứng xử hằng ngày chịu ảnh hưởng sâu đậm của môi trường. Đà Lạt với không khí ôn hòa, quang cảnh tươi đẹp là môi trường lý tưởng cho sự phát triển một phong cách lành mạnh, hài hòa. Nếu nghiên cứu kỹ, ta có thể thấy rằng thiên nhiên Đà Lạt tự nó đã góp phần đào luyện trí tuệ, tâm tính con người sinh ra trong lòng nó. Cách tư duy có lý có tình, lối nhìn sự vật một cách toàn diện dường như tiềm ẩn tự nhiên nơi họ (Ưy ban Nhân dân Thành phố Đà Lạt, 1993).

Trong lịch sử, cư dân Đà Lạt, ngoài tộc người Lạch bản địa cư trú lâu đời thì nguồn gốc dân cư có người Pháp, Châu Âu, người Kinh, và người Hoa đến sinh cơ lập nghiệp tại vùng đất cao nguyên này. Có thể nói, ngoài một số rất nhỏ người gốc Nam Bộ, phần lớn cư dân Đà Lạt đều có xuất xứ từ các tỉnh đồng bằng Bắc Bộ và miền Trung. Trong đó phải kể nhiều nhất là dân các tỉnh phụ cận Hà Nội, Nghệ Tĩnh, Trị Thiên, NamNgãi-Bình-Phú. Họ đến Đà Lạt mang theo truyền thống và bản sắc của những địa phương đã có độ dày bền vững và những nét cá biệt độc đáo không thể lẫn lộn được. Nói đến nguyên nhân của những thành tựu trong việc xây dựng, giữ gìn, và phát huy phong cách, lối sống của người Đà Lạt, chúng ta không thể quên người Pháp-họ đã hiện diện ngay từ những năm tháng đầu tiên khi cao nguyên này được khám phá. Theo ghi nhận, người Pháp xuất hiện ở Đà Lạt là những con người văn minh và lịch sự, khác hẳn với những lính viễn chinh trong những cuộc càn quét hay những ông chủ thực dân trong các đồn điền, hầm mỏ. 
Khi những kiến trúc sư người Pháp thiết lập nên những bản đồ quy hoạch và xây dựng những công trình đầu tiên tại Đà Lạt, họ đã góp phần không nhỏ trong việc vun đắp những giá trị văn hóa ngày càng mang tính đặc thù. Những dinh thự, biệt thự kiểu Pháp vẫn còn nguyên giá trị cho đến ngày nay và có lẽ đến mai sau. Đà Lạt ảnh hưởng sớm sự tiến bộ của văn minh phương Tây, nhưng lại nhanh chóng phù hợp với người Việt Nam. Sự hòa trộn tinh hoa của hai nền văn hóa Pháp-Việt đã thấm trong phong cách của người Đà Lạt ngày nay, không chỉ bộc lộ qua tính hiền hòa, đằm thắm, trung thực và lòng mến khách mà còn biểu hiện rõ nhất trong việc tạo nên những cảnh quan kiến trúc và không gian đô thị rất đặc biệt của một "thành phố trong rừng" hay "rừng trong thành phố" mà từ người dân bình thường đến các nhà quản lý đô thị, những kiến trúc sư trẻ đều có thể cảm nhận được (Trần, 2007).

Ngoài ra, những yếu tố về tư tưởng, tinh thần, tôn giáo, tín ngưỡng cũng góp phần xây dựng, giữ gìn, và phát huy phong cách người Đà Lạt hôm nay. Dù không là tất cả nhưng điều kiện kinh tế, mức sống cư dân, trình độ học vấn của người dân ngày càng cao, phong cách người Đà Lạt càng tao nhã và lịch sự hơn. Một chủ thể quyết định đến những thành tựu trong việc giữ gìn và phát huy phong cách người Đà Lạt đó chính là Nhà nước. Khuôn mặt đô thị, không gian sinh tồn, và phần lớn những hành vi cư xử và phong cách lối sống của người Đà Lạt và du khách chịu tác động mạnh mẽ bởi các công việc quản lý hàng ngày, buộc người có trách nhiệm phải luôn gương mẫu, đi đầu, phát huy tất cả trí tuệ, tâm huyết, xây dựng thành phố để xứng tầm là một đô thị hiện đại, phát triển bền vững, và xứng danh với sự hiền hòa, thân thiện, mến khách.

\subsubsection{Nguyên nhân của nhũng hạn chế trong giũ gìn và phát huy phong cách người Đà Lạt}

Trước hết, nói về môi trường cảnh quan và kiến trúc Đà Lạt hiện nay. Mặc dù, được xem là thành phố có tốc độ phát triển chậm chạp hơn các thành phố khác, nhưng dễ dàng chúng ta nhận thấy môi trường kiến trúc Đà Lạt có nhiều thay đổi quan trọng do quá trình công nghiệp hóa, hiện đại hóa đem lại. Qua phỏng vấn sâu người Đà Lạt về môi trường sinh sống, kiến trúc, nhà ở, đã có các ý kiến đáng suy ngẫm.

Đà Lạt hôm nay với việc đào đãi khoáng sản tùy tiện, đào núi, bạt đồi, lấp hồ, sự mất phương hướng của các kiến trúc đã góp tay phá vỡ cảnh quan Đà Lạt. Nguyên nhân đầu thuộc về một thành phố gần 30 năm sau giải phóng không có quy hoạch chiến lược, bộ máy quản lý lúng túng trong một thời cơ chế cũ không đối phó kịp thời với phong trào chiếm đất, tự động xây cất nhà ở, tự ý cơi nới công trình. Diện mạo kiến trúc Đà Lạt như đã định hình từ mảng nhà ở của dân bùng nổ theo một chiều hướng xấu đi. Những công trình lớn được xây dựng từ sau năm 1975 đến nay, người ta nhìn thấy những quan điểm như kiến trúc Đà Lạt hình như khác nhau, bởi thời gian quy hoạch trước đây và hiện nay khác xa nhau nên những công trình thiếu đi những mối dây liên hệ giữa đơn lẻ với tổng thể, giữa quá khứ với hiện tại và tương lai. Thậm chí có công trình giống như được bê từ một thành phố nào đó đến đặt ở đây, hoàn toàn không dính líu một tí gì với Đà Lạt. Những người quan tâm vẻ đẹp kiến trúc vốn có của Đà Lạt hết sức lo ngại trước chiều hướng xây dựng hiện đại các công trình bốn năm sao cho khách sạn và mảng nhà ở của nhân dân với mục 
đích nhằm phô trương tiện nghi sinh hoạt vất chất gia đình. Tất cả đang dẫn Đà Lạt đến một thành phố đầy dẫy container chứa hàng hóa của nền văn minh vật chất. Đà Lạt không cần thể hiện văn minh vật chất, hãy để cho các thành phố khác làm điều ây, Đà Lạt chỉ cần loại kiến trúc của tâm hồn.... Kiến trúc Đà Lạt không còn con đường nào khác hơn phải quay về chất cổ điển trên nền tảng tôn trọng tuyệt đối thiên nhiên (Mai, 1995).

Chúng ta cũng dễ dàng nhận thấy hiện nay sự hài hòa giữa màu xanh (màu của cỏ cây hoa lá tự nhiên) và màu xám (màu của các công trình kiến trúc, nhà ở) đã không còn nữa. Đà Lạt với nhu cầu mưu sinh và phát triển kinh tế đã khai thác tối đa diện tích đất đai. Việc phát triển kinh tế vườn với nghề làm rau, và trồng hoa đã đem lại nguồn thu nhập đáng kể cho người dân, hơn nữa do nhu cầu nhà ở, nhà nghỉ, khách sạn, và homestay cho du khách với số lượng ngày càng tăng đòi hỏi phải khai phá, xây dựng nhà cửa, và phát triển nhà kính phục vụ sản xuất đã làm cho diện mạo Đà Lạt không còn cân đối trong vẻ đẹp tự nhiên vốn có.

Đà Lạt hôm nay tuy cũng đồi núi chập chùng nhưng rừng đã không còn nhiều như trước, màu xanh đã loãng dần; Đà Lạt hôm nay, đường sá vẫn quanh co, uốn lượn nhưng đã to rộng hơn, hiện đại hơn không còn mềm mại đẹp như xưa; Đà Lạt hôm nay không còn "người lưa thưa chìm dưới sương mù", người đã đông đúc, xe cộ dập dìu, ồn ào, và sôi động; Đà Lạt đã nóng dần lên và sương mù cũng đã bớt giăng mờ khắp lối. Môi trường Đà Lạt cũng đã giảm đi sự trong lành. Đà Lạt đã bớt đi thơ mộng. Người Đà Lạt bây giờ không còn thong dong, chậm bước, mà nhịp sống đã hối hả hơn, thực dụng hơn. Báo chí đã nói rất nhiều về một Đà Lạt rác thải, một Đà Lạt lừa lọc, chèo kéo, "chặt chém" du khách, một Đà Lạt với hạ tầng giao thông thiếu sự an toàn. Đà Lạt bây giờ đã giảm đi chút hiền hòa, mai một đi chút thanh lịch, và thiếu vắng những nụ cười. Có thể không phải là tất cả nhưng có những con sâu đã làm rầu nồi canh... sự thật đó không thể phủ nhận (Lê, 2018).

Hiện nay, cần mạnh dạn nhìn thẳng vào thực tế để nói với nhau rằng, phong cách hiền hòa, thanh lịch, mến khách của người Đà Lạt đã mất đi nhiều lắm. Những người có phong cách nhẹ nhàng và tinh tế từ lời ăn tiếng nói đến cử chỉ và hành vi ngày càng có khuynh hướng ít dần để nhường chỗ cho sự xô bồ hay bỗ bã. Hiện nay, người ta ít sử dụng những từ xin lỗi hay cảm ơn, mà thay vào đó những từ khiếm nhã. Chính quyền cần phải mạnh tay hơn nữa đối với những hiện tượng chặt chém để du khách không phải phàn nàn khi đến với Đà Lạt (Nhóm nghiên cứu, 17/3/2019).

\section{KẾT LUẬN}

Qua phân tích, chúng ta thấy rằng Đà Lạt, một thành phố trên cao nguyên được thiên nhiên ban tặng cho một môi trường khí hậu tuyệt vời. Ngay từ đầu phát hiện và xây dựng, Đà Lạt đã được quy hoạch một cách bài bản, cẩn trọng bởi những kiến trúc sư người Pháp. Cùng với người Pháp, các nhóm cư dân Hà Nội, Thanh-Nghệ, Thừa Thiên Huế, NamNgãi-Bình-Phú, một số ít người Hoa, và người Nam Trung Bộ đến mưu sinh và lập nghiệp. Điều đặc biệt thú vị của vùng đất này giổng như một số các thành phố Bắc Mỹ, Canada 
không chỉ là môi trường khí hậu mát lành mà còn ở tính "đa văn hóa" của các cộng đồng cư dân. Vì thế, ngay từ những năm đầu tiên và cho tận ngày nay người Đà Lạt luôn luôn ứng xử một cách hiền hòa, thanh lịch, mến khách đối với những người mới đến sinh sống và du khách thập phương. Đà Lạt hôm nay còn một số vấn đề cần khắc phục, sửa chữa về kiến trúc, quy hoạch nhà ở, các vấn đề về phát triển nông nghiệp công nghệ cao với mật độ dày đặc các nhà kính trồng rau hoa, sự ô nhiễm môi trường nước, không khí do ảnh hưởng một lượng đáng kể hóa chất phục vụ nhu cầu sản xuất. Dân số Đà Lạt cũng gia tăng nhanh chóng trong những năm gần đây, nguồn gốc dân cư vốn đã có tính hỗn tạp và không thuần nhất thì ngày nay yếu tố này cũng trở nên đa dạng và phong phú hơn nhiều. Ngoài những người được xem là người Đà Lạt thì luôn có người nhập cư mới, mang theo văn hóa, phong cách, lối sống theo quá trình di thực địa lý. Dù vậy, với những tính chất ưu việt của một vùng đất màu mỡ, giàu tài nguyên thiên nhiên, và khí hậu quanh năm mát mẻ, người Đà Lạt ngày nay vẫn lưu giữ nét hiền hòa, thanh lịch, mến khách.

Dù quy luật tất yếu của sự phát triển kinh tế, xã hội, môi trường với những biến đổi xã hội không ngừng do quá trình đô thị hóa, nhưng Đà Lạt có quyền lựa chọn cho mình hướng phát triển riêng cho phù hợp, dựa trên toàn bộ cơ sở vật chất, điều kiện sống, tính chất các hoạt động nghề nghiệp và những mối quan hệ đa dạng các thành phần dân cư của thành phố. Về mặt lý luận, quá trình đô thị hóa có ba khuynh hướng: Đô thị hóa theo chiều rộng (tăng quy mô diện tích và dân số); Đô thị hóa theo chiều sâu (tập trung vào nâng cao chất lượng và điều kiện sống của thị dân); Đô thị hóa kết hợp cả hai khuynh hướng trên. Chính quyền và người dân thành phố hoàn toàn có thể lựa chọn, cân nhắc các mô hình phát triển để chắp cánh cho Đà Lạt phát triền bền vững, vững tin trên con đường hội nhập quốc gia, quốc tế, và xứng danh với thương hiệu "Đà Lạt- kết tinh kỳ diệu từ đất lành".

\section{TÀI LIỆU THAM KHẢO}

Hồ, T. T. (1997). Về phong cách Đà Lạt. Trong Báo Lâm Đồng, Nhũng bài báo chọn lọc (tr. 124-133). Lâm Đồng, Việt Nam: Xí nghiệp in bản đồ Đà Lạt.

Lê, T. V. (2018). Phong cách người Đà Lạt: Hai câu chuyện một góc nhìn. Bài báo được trình bày tại Hội thảo phát huy văn hóa ứng xử người Đà Lạt góp phần xây dựng hình ảnh du lịch Lâm Đồng Văn minh, Thân thiện, An toàn, Lâm Đồng, Việt Nam.

Mai, H. (1995). Kiến trúc Đà Lạt, sư trở về với thiên nhiên. Hà Nội, Việt Nam: NXB. Lao động.

Sở Văn hóa Thể thao và Du lịch tỉnh Lâm Đồng. (2020). Báo cáo tổng kết công tác văn hóa, thể thao và du lịch năm 2019, Phuơng huoóng nhiệm vụ năm 2020. Lâm Đồng, Việt Nam.

Trần, L. Đ. (2007). Đất và người Tây nguyên. Thành phố Hồ Chí Minh, Việt Nam: NXB. Văn hóa Sài Gòn.

Ủy ban Nhân dân thành phố Đà Lạt. (1993). Đà Lạt thành phố cao nguyên. Thành phố Hồ Chí Minh, Việt Nam: NXB. Tổng hợp Thành phố Hồ Chí Minh.

Uông, B. T. (2018). Nhân dân điện tử. Được truy lục từ:https://www.nhandan.org.vn/ vanhoa/item/35590602-net-thanh-lich-cua-nguoi-da-lat.html. 